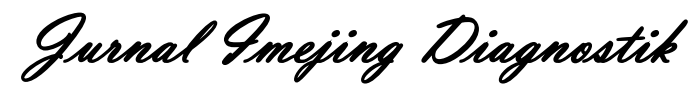

e-ISSN 2621-7457, p-ISSN 2356-301X http://ejournal.poltekkessmg.ac.id/ojs/index.php/iimed/index

\title{
Hasil Gambaran Fase non delay dengan Fase delay di Area Bladder pada Pemeriksaan PET/CT
}

\author{
Dimas Prakoso $^{1)}$, Gatot Murti Wibowo ${ }^{1)}$, Ratianto $^{2)}$ \\ ${ }^{1)}$ Program Pascasarsajana, Magister Terapan Kesehatan Imaging Diagnostik Poltekkes Kemenkes Semarang, \\ Indonesia \\ 2) MRCCC Siloam Hospital Semanggi, Jakarta, Indonesia \\ e-mail : dimas.kepodang@gmail.com
}

Received: Mei $17^{\text {th }}, 2019$; Revised: June $23^{\text {th }}, 2019$; Accepted: July $02^{\text {nd }}, 2019$

\begin{abstract}
Background : PET/CT examination is an examination performed by injection of a radiopharmaceutical that consist of ${ }^{18}$ F-FDG which given intravenously to evaluate lesions in whole body. However, some PET/CT examination using delay phase for certain pathologies and if the doctor unsure about the resultiong image. This study peform the difference image in quantitative of PET/CT examination between non-delay phase and delay phase in area bladder and surrounding.

Methods : The type of research conducted is quantitatif research with a case study approach, the research that provides a detail description of the actual situation in the hospital. Subjects consist of radiographers, nuclear medicine specialist, and scientific literature and objects are the images of non delay and delay phase PET/CT in the bladder area. Data is taken by observation, interview, and documentation.

Results : Assessment image of PET/CT using the value of SUV by ROI on several organ such us the baldder, rectum, ileum, and sacrum. In the non delay and delay phase, the value of the SUV was compared and the result on rectum area was increased, in other organ such as the bladder, ileum, and sacrum the value of SUV was decreased.

Conclutions : The difference of image between non delay and delay phase can be seen from the value of SUV organ. SUV value can high in the bladder area because of the accumulation of FDG and scanning from the head so when scanning the pelvis value of SUV is high and can infuluence the image of surrounding organs.
\end{abstract}

Keywords : PET/CT; non delay phase; delay phase; SUV; bladder.

\section{Pendahuluan}

Kedokteran nuklir merupakan cabang ilmu kedokteran yang menggunakan sumber radiasi terbuka dari disintegrasi inti radionuklida buatan (radiofarmaka) untuk tujuan diagnostik, terapi, dan paliatif dengan berdasarkan perubahan fisiologi, anatomi, biokimia, metabolisme, dan molekuler dari organ tubuh. Dalam pelayanannya, radioisotop dimasukkan tubuh pasien (in vivo) atau direaksikan bahan biologis (in vitro). Dalam hal pencitraan, terdapat dua jenis pencitraan yang dapat digunakan untuk menghasilkan gambaran dari radiofarmaka tubuh yaitu Positron Emission Tomography (PET) dan Single Photon Emission Computed Tomography (SPECT) (Z. Alatas et al, 2015).

Dalam aplikasinya pemindaian PET menjadi teknologi tomografi gabungan atau hibrid dengan digabungkan dengan CT Scan untuk memperoleh informasi secara struktural dan fungsional dalam satu pencitraan. Data yang saling melengkapi pada CT Scan untuk melihat lokasi serta menentukan presisi lokasi, volume lesi, dan karakteristik dari lesi yang dihasilkan dan PET digunakan untuk menyoroti area metabolisme yang abnormal (A. Karellas and B. R. Thomadsen, 2017). PET menghitung distribusi radioaktivitas secara tiga dimensi (3D) berdasarkan foton yang saling menghilangkan muatan (annihilation) yang dipancarkan oleh positron dan PET memungkinkan penilaian kuantitatif secara proses biokimia dan fungsional ${ }^{[3]}$. Untuk dapat menghasilkan gambaran yang baik dan diagnosa yang akurat dengan menggunakan PET/CT, diperlukan beberapa persiapan dan komunikasi yang baik sebelum melakukan pemeriksaan ${ }^{[4]}$. Persiapan dimulai dari adanya koordinasi antara radiofarmasi dan radiografer. Perlu mengetahui informasi pasien termasuk riwayat diabetes, berat badan untuk 
menentukan dosis, dan edukasi persiapan sebelum pemindaian. Sebelum melakukan pemeriksaan PET, kadar gula darah sewaktu (GDS) pasien dipantau $\leq 150 \mathrm{mg} / \mathrm{dL}$, pasien melakukan puasa 4 6 jam sebelum pemeriksaan (R. Boellaard et al., 2015).

Pemeriksaan PET/CT dilakukan dengan penyuntikan ${ }^{18} \mathrm{~F}$ FDG dengan dosis $10-20 \mathrm{mCi} / \mathrm{kg}$ berat badan pasien. Pemindaian dilakukan 1 jam setelah injeksi, penilaian dari PET/CT dengan ${ }^{18} \mathrm{~F}$ FDG dilihat dari Standarized Uptake Value (SUV) yang merupakan uptake ${ }^{18} \mathrm{~F}$ FDG pada CT yang membedakan citra lesi ganas dan jinak (R. Boellaard et al., 2015). SUV dipengaruhi oleh beberapa faktor, seperti berat badan pasien, ekstravasasi dosis, parameter atenuasi, parameter rekonstruksi, efek volume parsial, dan kadar glukosa plasma darah. SUV dapat dilihat dari Region of Interest (ROI) organ, nilai SUV yang digunakan untuk mengevaluasi adalah SUVmax karena tidak dipengaruhi oleh efek volume parsial dan merpakan nilai piksel maksimal dalam irisan gambar (S. Soongsathitanon, P. Masa-ah, and M. Tuntawiroon, 2012). Pada beberapa kasus seperti tumor ganas di soft tissue atau jaringan lunak diperlukan adanya fase delay atau penambahan waktu pemeriksaan setelah pemeriksaan awal selesai dilakukan, dengan penambahan fase delay ini dapat melihat perbedaan antara tumor ganas atau tumor jinak terutama pada muskuloskeletal, waktu pemindaian fase delay dilakukan 2 jam setelah injeksi untuk dapat melihat perbedaan antara tumor ganas dan jinak secara akurat (R. V Parghane and S. Basu., 2.017)

Menurut (S. Harkirat, S. S. Anand, and M. J. Jacob, 2010) dan (Y.-Y. Lu et al., 2011) penggunaan fase delay dapat melakukan evaluasi terhadap kanker kandung kemih invasif dibandingkan hanya CT saja ${ }^{[8], \text { [9] }}$. Pemberian obat diuretik seperti furosemid pada fase ini dapat digunakan untuk melihat penyebaran kanker atau pengobatan kanker dalam kandung kemih ${ }^{[8]}$. Dalam organ serviks diperlukan fase delay yang digunakan untuk mendeteksi kelainan metastases pada Paraoartic Lymph Node (PALN) di prostat dengan waktu delay 3 jam (M. A. Mortensen et al., 2018). Berdasarkan latar belakang tersebut, penulis tertarik untuk mengkaji lebih dalam dengan bentuk kajian ilmiah dengan judul perbedaan hasil gambaran fase non delay dengan fase delay di area bladder pada pemeriksaan PET/CT.

\section{Metode}

Jenis penelitian ini adalah penelitian kualitatif dengan pendekatan studi kasus, yaitu penelitian yang memberikan gambaran keadaan yang sebenarnya di lapangan. Pengambilan data dilakukan di Instalasi Kedokteran nuklir salah satu Rumah Sakit di Jakarta pada bulan September 2018. Metode pengambilan data yang dilakukan dengan observasi dan ikut serta berberan aktif melakukan wawancara untuk mendapatkan data dan informasi, serta studi dokumen dari pustaka berupa jurnal dan dokumen yang berkaitan dengan penelitian ini.

\section{Hasil dan Pembahasan}

Pemeriksaan PET/CT dilakukan dengan injeksi ${ }^{18} \mathrm{~F}$-FDG terlebih dahulu melalui intravena 1 jam sebelum pemeriksaan dilakukan. Fase awal pemeriksaan merupakan fase non delay dan dilakukan scanning dari kepala sampai lutut. Pada kasus ini dilakukan fase delay yang dilakukan 2 jam setelah injeksi (60 menit dari scan pertama). Fase delay diperlukan untuk dapat mengevaluasi lebih lanjut daerah sekitar kadung kemih terutama pasien ini karena klinis ca ovarium. Pemindaian fase delay pada kasus ini hanya daerah pelvis yang meliputi Lumbal III sampai 1/3 proximal femur.

Pemindaian baik fase non delay dan fase delay dilakukan sebanyak dua tahap, pada pemindaian pertama merupakan gambaran CT Scan yang digunakan untuk topogram, dilanjutkan pemindaian PET. Sebelum pemindaian PET dilakukan perlu dimasukkan data dosis radiofarmaka yang telah diinjeksikan, waktu injeksi radiofarmaka, dan waktu saat akuisisi PET/CT. Pengukuran kuantitatif dilakukan dengan menggunakan nilai $\mathrm{SUV}_{\max }$ organ yang dicurigai patologi.

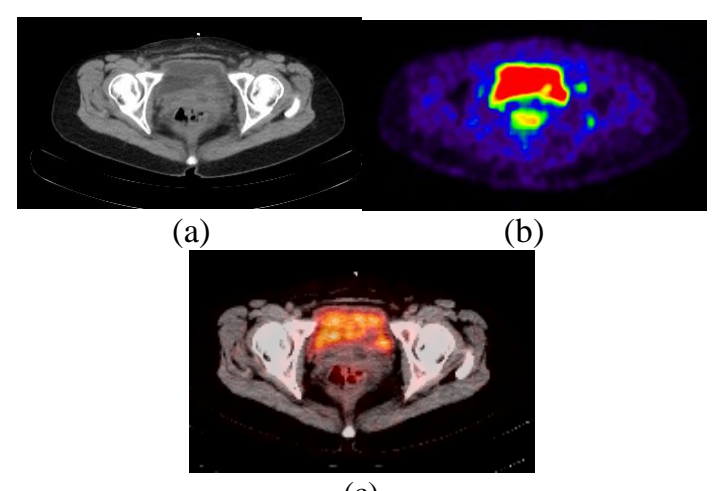

(c)

Gambar 1. Gambaran non delay PET/CT. (a) Gambaran hasil CT Scan, (b) Gambaran hasil PET, dan (c) Gambaran Fusi $\mathrm{PET} / \mathrm{CT}$

Evaluasi dilakukan menggunakan gambaran fusi seperti gambar (c) pada gambar 1. Gambaran fusi merupakan gabungan yang didapatkan dari gambaran CT scan (gambar a) dan gambaran PET (gambar b). Untuk menilai tiap organ dapat 
dilakukan dengan membandingkan nilai $\mathrm{SUV}_{\max }$ dengan cara membuat ROI pada kandung kemih dan area disekitarnya seperti rektum, tulang ilium, dan sacrum. Hasil dari nilai $\mathrm{SUV}_{\max }$ dapat dilihat seperti gambar 2-5.

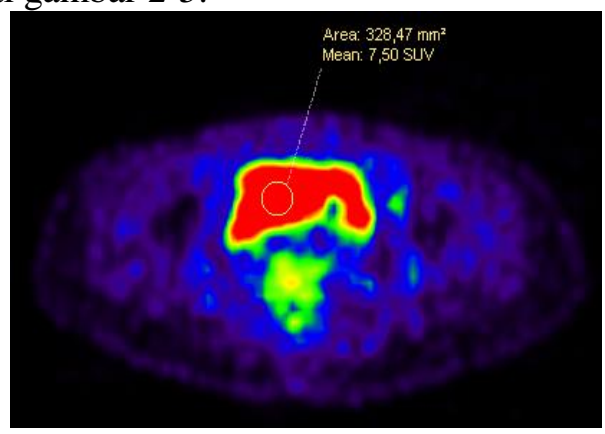

(a)

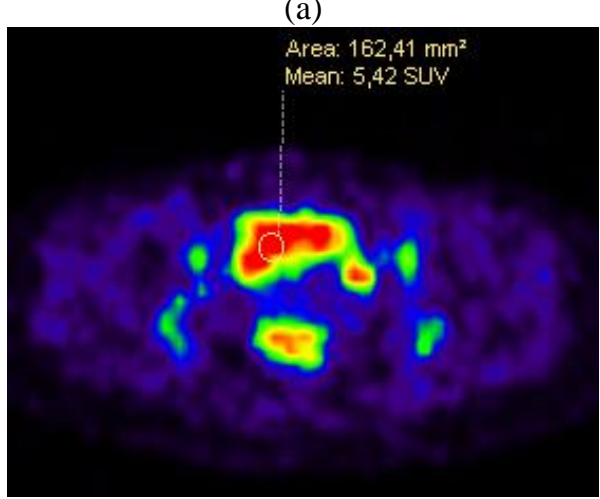

(b)

Gambar 2. Perbedaan nilai SUV $\mathrm{max}_{\max }$ organ kandung kemih (a) non delay (b) delay organ kandung kemih Nilai $\mathrm{SUV}_{\max }$ pada organ bladder pada saat non delay adalah 7,50 dan pada pemindaian delay $\mathrm{SUV}_{\max }$ mengalami penurunan dan nilainya menjadi 5,42.

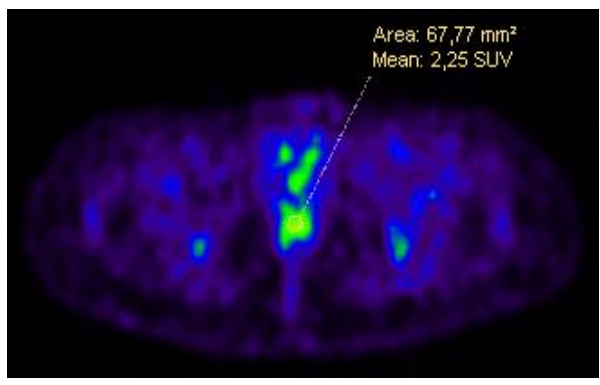

(a)

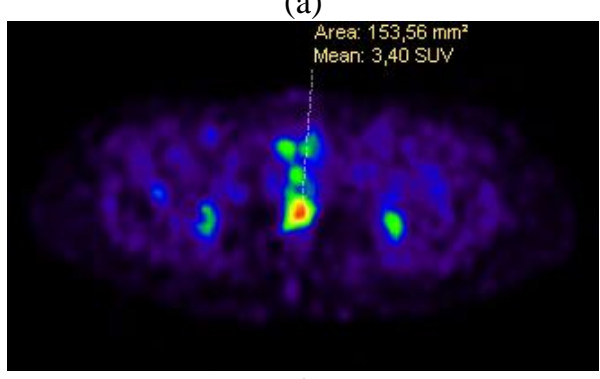

(b)

Gambar 3. Perbedaan nilai $\mathrm{SUV}_{\max }$ organ rektum (a) non delay (b) delay organ rektum
Nilai $\mathrm{SUV}_{\max }$ pada daerah rektum juga mengalami peningkatan pada fase non delay adalah 2,25 dan pada fase delay nilainya adalah 3,40

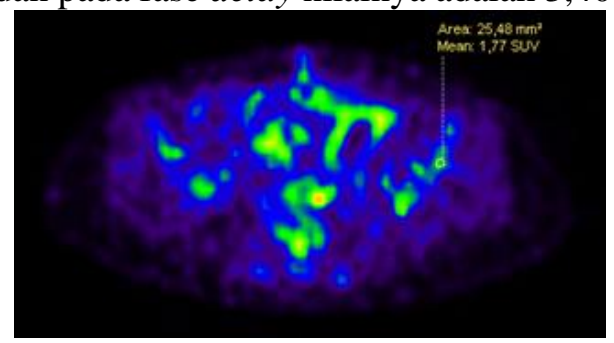

(a)

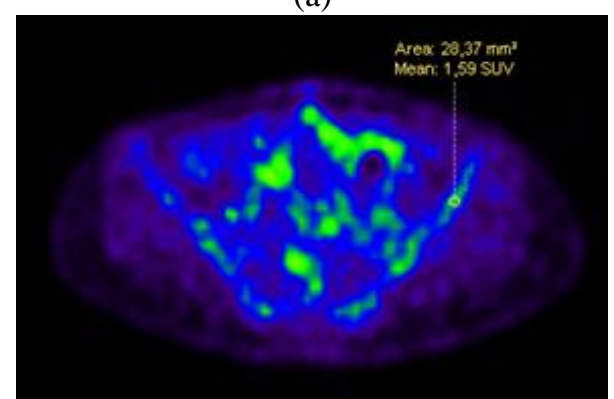

(b)

Gambar 4. Perbedaan nilai $\mathrm{SUV}_{\max }$ tulang ileum (a) non delay (b) delay organ ileum

Pada organ tulang ileum nilai $\mathrm{SUV}_{\max }$ mengalami penurunan nilai antara fase non delay dan fase delay. Pada fase non delay nilai $\mathrm{SUV}_{\max }$ adalah 1,77 dan pada fase delay nilai $\mathrm{SUV}_{\max }$ adalah 1,59 .

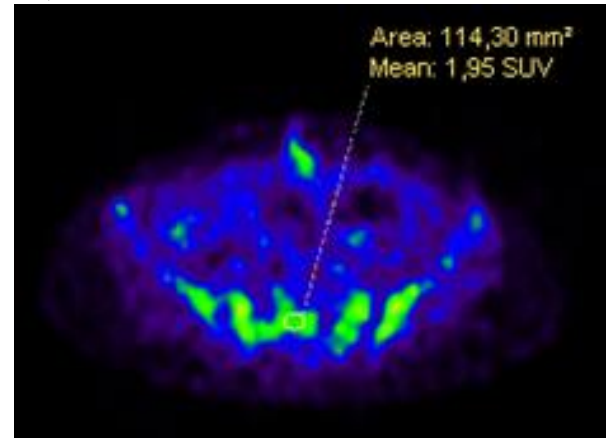

(a)

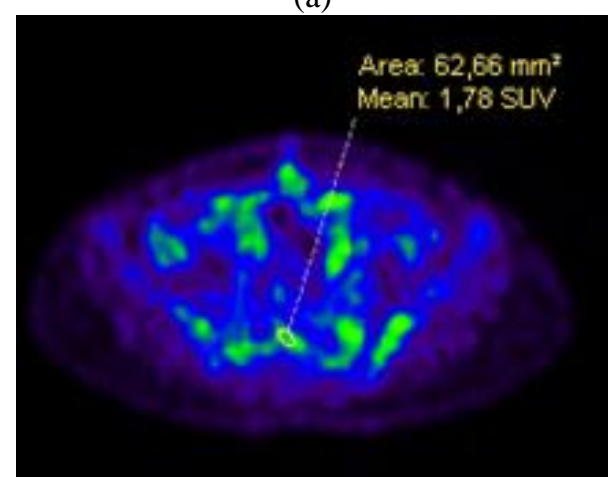

(b)

Gambar 5. Perbedaan nilai SUV max $_{\text {ax }}$ tulang sakrum (a) non delay (b) delay organ sakrum

Pada organ tulang sakrum nilai $\mathrm{SUV}_{\max }$ mengalami penurunan nilai antara fase non delay dan fase delay. Pada fase non delay nilai $\mathrm{SUV}_{\max }$ 
adalah 1,95 dan pada fase delay nilai $\mathrm{SUV}_{\max }$ adalah 1,79. Berdasarkan hasil penghitungan $\mathrm{SUV}_{\max }$ melalui ROI pada organ tertentu pada gambar 2, 3, 4, dan 5 dapat disimpulkan sebagai berikut.

Tabel 1. Perbandingan Nilai $\mathrm{SUV}_{\max }$ non delay dan delay di daerah Pelvis

\begin{tabular}{lccc}
\hline \multicolumn{1}{c}{ Nama Organ } & $\begin{array}{c}\mathrm{SUV}_{\max } \text { non } \\
\text { delay }\end{array}$ & $\begin{array}{c}\mathrm{SUV}_{\max } \\
\text { delay }\end{array}$ & Kesimpulan \\
\hline Kandung Kemih & 7,50 & 5,42 & Penurunan \\
Rektum & 2,25 & 3,40 & Kenaikan \\
Ileum & 1,77 & 1,59 & Penurunan \\
Sakrum & 1,95 & 1,79 & Penurunan \\
\hline
\end{tabular}

Beberapa kasus PET/CT memerlukan fase delay untuk kasus patologi tertentu dan dilakukan apabila dokter kurang yakin terhadap gambaran yang dihasilkan untuk mendapatkan informasi tambahan pada jenjang waktu yang berbeda. Perbedaan dapat dilihat dari daerah kandung kemih karena terjadi pengumpulan ${ }^{18} \mathrm{~F}-\mathrm{FDG}$ untuk di sekresi. Pada fase non delay dapat dilihat dari gambar 2 penangkapan uptake di daerah kandung kemih mengalami penangkapan yang tinggi karena akuisisi dilakukan dari organ kepala, hal ini membutuhkan waktu yang lebih lama sekitar 12 15 menit untuk pencitraan daerah pelvis sehingga hasil akumulasi pada daerah bladder lebih banyak, dari ROI didapat nilai $\mathrm{SUV}_{\max }$ yang tinggi yaitu 7,50 dan menyebabkan menutupi beberapa organ disekitar. Pada fase delay setelah 2 jam pasca injeksi, nilai $\mathrm{SUV}_{\max }$ menjadi 5,42. Penurunan intensitas ${ }^{18}$ F-FDG pada fase delay di kandung kemih dapat digunakan mengevaluasi organ lain yang tertutup dengan kandung kemih sebelumnya. Sebelum fase delay dilakukan pastikan pasien melakukan sekresi urin agar penumpukan ${ }^{18} \mathrm{~F}-\mathrm{FDG}$ dapat berkurang dibandingkan fase non delay, apabila fase delay dan non delay nilai hampir sama atau lebih tinggi pada fase non delay dapat dicurigai adanya patologi pada organ pada kandung kemih tersebut.

Pada rektum seperti pada gambar 3, mengalami peningkatan uptake, hal ini disebabkan ${ }^{18}$ F-FDG menumpuk di saluran sekresi di daerah tersebut dan belum dikeluarkan. Pada organ tulang ileum gambar 4 dan sakrum 5 nilai $\mathrm{SUV}_{\max }$ antara fase non delay dan fase delay mengalami penurunan uptake disebabkan ${ }^{18} \mathrm{~F}-\mathrm{FDG}$ dalam tulang mengalami proses metabolisme dan proses akhir dari proses metabolisme akan dikeluarkan tubuh atau sekresi. Pada gambar 4 juga dapat dilihat organ daerah genetalia pada fase non delay hampir semua organ melakukan penangkapan terhadap ${ }^{18}$ F-FDG dan pada fase delay organ yang menangkap ${ }^{18} \mathrm{~F}-\mathrm{FDG}$ tersebut mulai berkurang intensitasnya.

Selain untuk evaluasi terhadap gambaran kandung kemih yang memiliki kadar ${ }^{18} \mathrm{~F}-\mathrm{FDG}$ yang tinggi, fase delay dapat digunakan untuk memastikan patologi apakah lesi jinak atau lesi ganas dengan membandingkan nilai $\mathrm{SUV}_{\max }$ pada fase non delay dengan fase delay. Beberapa penelitian telah melakukan perbandingan nilai $\mathrm{SUV}_{\max }$ antara fase non delay dengan fase delay area yang dicurigai dengan melihat nilai RI. Nilai RI pada organ daerah pelvis pada wanita seperti ovarium, uterus, dan serviks yang melebihi 11 dapat dikategorikan menjadi lesi ganas, dan apabila kurang dari 11 dikategorikan sebagai lesi jinak.

\section{Simpulan}

Fase non delay dilakukan 60 menit post injeksi ${ }^{18}$ F-FDG dan fase delay dilakukan 120 menit post injeksi ${ }^{18}$ F-FDG. Pada fase non delay, akumulasi ${ }^{18}$ F-FDG pada kandung kemih meningkat dan dapat menganggu penilaian di area bladder, hal ini disebabkan uptake ${ }^{18}$ F-FDG yang cukup tinggi pada daerah tersebut. Gambaran fase non delay dan fase delay dapat dilihat dari uptake ${ }^{18}$ F-FDG yang ada di kandung kemih yang dapat menganggu evaluasi di sekitar daerah tersebut. Gambaran fase non delay dan fase delay dapat dibedakan juga dari penangkapan ${ }^{18} \mathrm{~F}-\mathrm{FDG}$ di organ rektum, tulang ileum, dan sakrum dari nilai $\mathrm{SUV}_{\max }$ yang dihasilkan. Rektum mengalami kenaikan nilai $\mathrm{SUV}_{\max }$ karena merupakan sekresi tubuh terakhir, pada tulang ileum dan sakrum penangkapan ${ }^{18} \mathrm{~F}-\mathrm{FDG}$ mengalami penurunan diakibatkan proses metabolisme tubuh. Fase delay dapat digunakan untuk membandingkan nilai $\mathrm{SUV}_{\max }$ dengan fase non delay untuk memastikan patologi termasuk lesi jinak atau lesi ganas dari nilai RI.

Untuk pemindaian PET/CT patologi pada daerah pelvis lebih baik akuisisi dilakukan dari daerah kaki ke kepala agar saat pemindaian belum terjadi akumulasi ${ }^{18}$ F-FDG daerah kandung kemih dan perlu dipastikan pasien melakukan sekresi urin sebelum dilakukan pemeriksaan.

\section{Daftar Pustaka}

A. Karellas and B. R. Thomadsen, Physics of PET and SPECT Imaging. Taylor \& Francis Group, 2017.

G. B. Saha, Basics of PET Imaging, Third Edit. Spinger, 2016.

M. A. Mortensen et al., "A prospective study on dual time F - FDG - PET / CT in high - risk prostate cancer patients," BMC Res. Notes, pp. 2-5, 2018. 
R. Boellaard, "Chapter 3: PET Imaging Instrumentation and Principles of PET Protocol Optimisation," 2010.

R. Boellaard et al., "FDG PET and PET / CT : EANM procedure guidelines for tumour PET imaging: version 1.0," J. Nucl. Med. Imaging, pp. 181-200, 2009.

R. V Parghane and S. Basu, "Dual-time point 18FFDG-PET and PET/CT for Differentiating Benign From Malignant Musculoskeletal Lesions Opportunities and Limitations," Semin. Nucl. Med., 2017.

S. Harkirat, S. S. Anand, and M. J. Jacob, "Forced diuresis and dual-phase 18F-fluorodeoxyglucosePET / CT scan for restaging of urinary bladder cancers," pp. 13-20, 2010.

S. Soongsathitanon, P. Masa-ah, and M. Tuntawiroon, "A new Standard Uptake Values ( SUV ) Calculation based on Pixel Intensity Values," vol. 6, no. 1, pp. 26-33, 2012.

Y.-Y. Lu et al., "Clinical value of FDG PET or PET / CT in urinary bladder cancer : A systemic review," vol. 81, pp. 2411-2416, 2011.

Z. Alatas et al., Buku Pintar Nuklir. Batan, 2015. 